\title{
UK Renal Registry 15th Annual Report: Chapter 7 Clinical, Haematological and Biochemical Parameters in Patients Receiving Renal Replacement Therapy in Paediatric Centres in the UK in 2011: National and Centre-Specific Analyses
}

\author{
Rishi Pruthi ${ }^{a}$, Heather Maxwell ${ }^{b}$, Anna Casula $^{a}$, Fiona Braddon $^{a}$, Malcolm Lewis ${ }^{c}$, \\ Catherine $\mathrm{O}^{\prime}$ Brien $^{\mathrm{d}}$, Yincent Tse ${ }^{\mathrm{e}}$, Carol Inward ${ }^{\mathrm{f}}$, Manish D Sinha ${ }^{\mathrm{g}}$

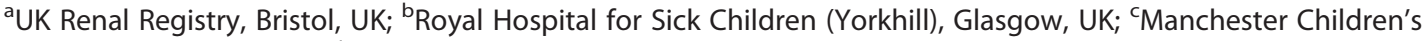 \\ Hospital, Manchester, UK; ${ }^{\mathrm{d} B i r m i n g h a m ~ C h i l d r e n ' s ~ H o s p i t a l, ~ B i r m i n g h a m, ~ U K ; ~}{ }^{e}$ Royal Victoria Infirmary, Newcastle, UK; \\ ${ }^{\mathrm{f} B r i s t o l}$ Royal Hospital for Children, Bristol, UK; ${ }^{9}$ Evelina Childrens Hospital, London, UK
}

\section{Key Words}

Biochemical variables · Children · Dialysis · ERF · Haemoglobin $\cdot$ Height $\cdot$ Quality improvement $\cdot$ Transplant $\cdot$ Weight

\begin{abstract}
Background: The British Association for Paediatric Nephrology Registry was established to analyse data related to renal replacement therapy (RRT) in children. The registry receives data from the 13 paediatric nephrology centres in the UK. Aims: To provide centre specific data so that individual centres can reflect on the contribution that their data makes to the national picture and to determine the extent to which their patient parameters meet nationally agreed audit standards for the management of children with established renal failure. Methods: Data returns have been a mixture of electronic and paper returns. Data were analysed to calculate summary statistics and where applicable the percentage achieving an audit standard. The standards used were those set out by the Renal
\end{abstract}

Association and the National Institute for Health and Clinical Excellence. Results: Anthropometric data confirmed that children receiving RRT were short compared to healthy peers. Amongst patients with a height of $<2$ SD between 2001 and 2011,31\% were receiving growth hormone if they were on dialysis compared to $10 \%$ if they had a functioning transplant. Blood pressure control remained challenging with wide inter-centre variation although this was significantly better in children with a functioning transplant. Over a third of haemodialysis patients and a quarter of peritoneal dialysis patients were anaemic, compared to only $7 \%$ of transplanted patients. ESA use in the dialysis population exceeded $90 \%$ amongst anaemic patients. The control of renal bone disease remained challenging. Conclusions: Optimizing growth in children on RRT remained challenging and the control of bone biochemistry in children on dialysis was imperfect. The likelihood of complete electronic reporting in the near future with plans for quarterly reporting in the format of the recently finalised NEW paediatric dataset will hopefully improve quality of data and their reporting, allowing improvements in patient care.

\section{KARGER}

Fax +4161306 1234 E-Mail karger@karger.ch www.karger.com
(C) 2013 S. Karger AG, Basel

$1160-2110 / 13 / 1235-0151 \$ 38.00 / 0$

Accessible online at: www.karger.com/nec
Manish D Sinha

UK Renal Registry, Southmead Hospital, Southmead Road Bristol, BS10 5NB, UK

Email: renalregistry@renalregistry.nhs.uk 


\section{Introduction}

This report focuses on the following variables for the prevalent paediatric dialysis and transplantation cohort on 31st December 2011:

1. The completeness of data returns to the renal registry

2. The anthropometric characteristics in children with established renal failure (ERF)

3. Blood pressure control in children with ERF

4. Anaemia control in children with ERF

5. Key biochemical findings in this population.

Analyses of prevalent paediatric patients aged $<16$ years receiving renal replacement therapy for the year 2011 and for the period 2000 to 2011 inclusive are reported. A single dataset was collected for each patient per year during this time period. Due to low numbers of patients in each cohort, no incident cohort analyses have been undertaken. Centre specific data for each paediatric nephrology centre in the UK has also been provided.

\section{Methods}

There were 13 centres providing care for children requiring renal replacement therapy in the UK, ten of which also provided surgical renal transplant services. All 13 centres provided outpatient and inpatient follow up for children who had received kidney transplants. Centres are listed in table 7.1 and appendix K.

\section{Data collection}

The data presented in this report relate to the annual census date of 31st December 2011.

Those paediatric centres with access to renal IT systems submitted encrypted electronic data directly to the UKRR. Those centres without access, sent paper or electronic returns in the original BAPN database format which were then entered into the original BAPN database as in previous years. Complete transfer to the UKRR encrypted database is still awaited.

\section{Governance, reporting and standardisation}

Information governance, reporting and standardisation were all performed in an identical manner to previous analyses to allow comparison [1]. With the value of many clinical parameters in childhood varying with age and size, data are presented as z-scores.

\section{Anthropometry}

The reference range for height $(\mathrm{Ht})$, weight $(\mathrm{Wt})$ and body mass index (BMI) in childhood varies with gender and age. $\mathrm{BMI}$ was calculated using the formula $\mathrm{BMI}=\mathrm{Wt}(\mathrm{kg}) / \mathrm{Ht}(\mathrm{m})^{2}$.
Table 7.1. Paediatric renal centres, their abbreviations and IT systems

\begin{tabular}{|c|c|c|}
\hline Paediatric centre & Abbreviation & $\begin{array}{l}\text { Renal } \\
\text { IT system }\end{array}$ \\
\hline Belfast $^{*}$ & Blfst_P & Medigal \\
\hline Birmingham & Bham_P & Proton \\
\hline Bristol & Brstl_P & Proton \\
\hline Cardiff & Cardf_P & Proton \\
\hline Glasgow & Glasg_P & Filemaker \\
\hline Leeds & Leeds_P & Proton \\
\hline Liverpool & Livpl_P & None \\
\hline London Evelina ${ }^{* *}$ & L Eve_P & Proton \\
\hline London Great Ormond Street ${ }^{* *}$ & L GOS̈H_P & Proton \\
\hline Manchester & Manch_P & Filemaker \\
\hline Newcastle $^{*}$ & Newc_P & $\begin{array}{l}\text { Clinical } \\
\text { Vision }\end{array}$ \\
\hline Nottingl & Nottm_P & Proton \\
\hline Southampton ${ }^{* * *}$ & Soton_P & Bespoke \\
\hline
\end{tabular}

${ }^{\star}$ New system installed, although paper submissions received in 2011

${ }^{*}$ Both London centres have a link to the PROTON system in Bristol but with no lab links

${ }^{* * *}$ Recent implementation of a bespoke renal IT system has enabled transmission of a limited dataset from Southampton this year

Height, weight and BMI were all adjusted for age and z-scores were calculated based on the British 1990 reference data for height and weight [2].

Blood pressure (BP)

The reference range for blood pressure varies with gender, age and height. The data is therefore presented as z-scores based on data from the fourth report of the National High Blood Pressure Education Programme (NHBPEP) working group in the United States [3].

\section{Laboratory values}

Haemoglobin ( $\mathrm{Hb})$, ferritin (Ferr), calcium (Ca) and phosphate (Phos) were analysed using age related laboratory reference ranges as in table 7.2. Data analysis is presented for each centre individually and at a national level for each variable.

\section{Statistical analyses}

Data were analysed to calculate summary statistics (maximum, minimum, mean and median values in addition to standard deviation and quartile ranges). Where applicable, the percentage achieving the audit standard was also calculated. If a patient had missing data, they were excluded from the relevant analyses.

Longitudinal analyses of attainment of standards over time were also performed. These were based on a single data point per ERF patient per year collected as described 
Table 7.2 Summary of relevant biochemical clinical audit measures

\begin{tabular}{|c|c|c|c|c|}
\hline \multirow[b]{2}{*}{ Parameter } & \multicolumn{4}{|c|}{ Age } \\
\hline & $<1$ year & $1-5$ years & $6-12$ years & $>12$ years \\
\hline Ferritin $(\mu \mathrm{g} / \mathrm{L})$ & $200-500$ & $200-500$ & $200-500$ & $200-500$ \\
\hline eGFR $\mathrm{ml} / \mathrm{min} / 1.73 \mathrm{~m}^{2}$ (transplant patients) & \multicolumn{4}{|c|}{$\begin{array}{c}\text { Estimated GFR (eGFR) as per Schwartz formula: (height } \mathrm{x} k \text { )/plasma creatinine. } \\
\text { The value for } \mathrm{k} \text { is that in use at the reporting centre }\end{array}$} \\
\hline $\begin{array}{l}\text { Parathyroid hormone (individual centre } \\
\text { units) }\end{array}$ & \multicolumn{4}{|c|}{$\begin{array}{l}\text { Within twice the normal range } \\
\text { Levels may be maintained within normal range if growing appropriately }\end{array}$} \\
\hline
\end{tabular}

previously. Cautious interpretation of these analyses is required due to changing audit standards over time and variable data returns for previous years. All analyses were done using SAS 9.3.

\section{Standards}

Standards are from the treatment of adults and children with renal failure, Renal Association 2002 guidelines [4] unless otherwise stated.

\section{Anthropometry}

'Height and weight should be monitored at each clinic visit. Measures of supine length or standing head circumference should be measured during each visit up to two years of age and 6 monthly up to 5 years of age. All measurements should be plotted on European reference growth charts for healthy children.'

\section{Blood pressure}

'Blood pressure varies throughout childhood and should be maintained within 2 standard deviations of the mean for normal children of the same height and sex. Systolic blood pressure during PD or post-HD should be maintained at $<90$ th percentile for age, gender and height.'

The analyses of blood pressure in this report present the achievement of blood pressures at or below the 90th percentile.

\section{Anaemia}

Guidance on the management of anaemia in adults and children with chronic kidney disease was updated and published by the National Institute for Clinical Excellence (NICE) in February 2011 (Clinical Guideline 114) [5]. The recommendation in this guidance is that in children with chronic kidney disease, treatment should maintain stable haemoglobin levels between 10 and $12 \mathrm{~g} / \mathrm{dl}$ in children above 2 years of age and between 9.5 and $11.5 \mathrm{~g} / \mathrm{dl}$ in children below 2 years of age. These NICE standards have been adopted for this report.

\section{Calcium, phosphate and parathyroid hormone (PTH) levels}

Phosphate and calcium should be kept within the normal range [4]. For analyses of calcium and phosphate, the age related ranges as described previously have been used [1]. PTH levels should be kept less than twice the upper limit of normal.

\section{Results}

\section{Data completeness}

Tables 7.3 and 7.4 show the completeness of data returns for transplant and dialysis patients for 2011.

In 2011, overall completeness was good, with virtually all data variables showing a significant rise in completeness compared to 2010 especially within the dialysis population. The exceptions were data returns for ferritin, IV Iron and EPO which showed modest rises, or a slight fall in some cases. This was attributed to some centres being unable to technically submit data, whilst other centres cited they were adopting to monitor transferrin saturations as an alternative to measuring ferritin levels which may have longer term consequences on future analyses. Cholesterol returns continued to remain poor 
Table 7.3. Percentage data completeness for transplant patients $<16$ years old by centre for each variable and total number of patients per centre in 2011

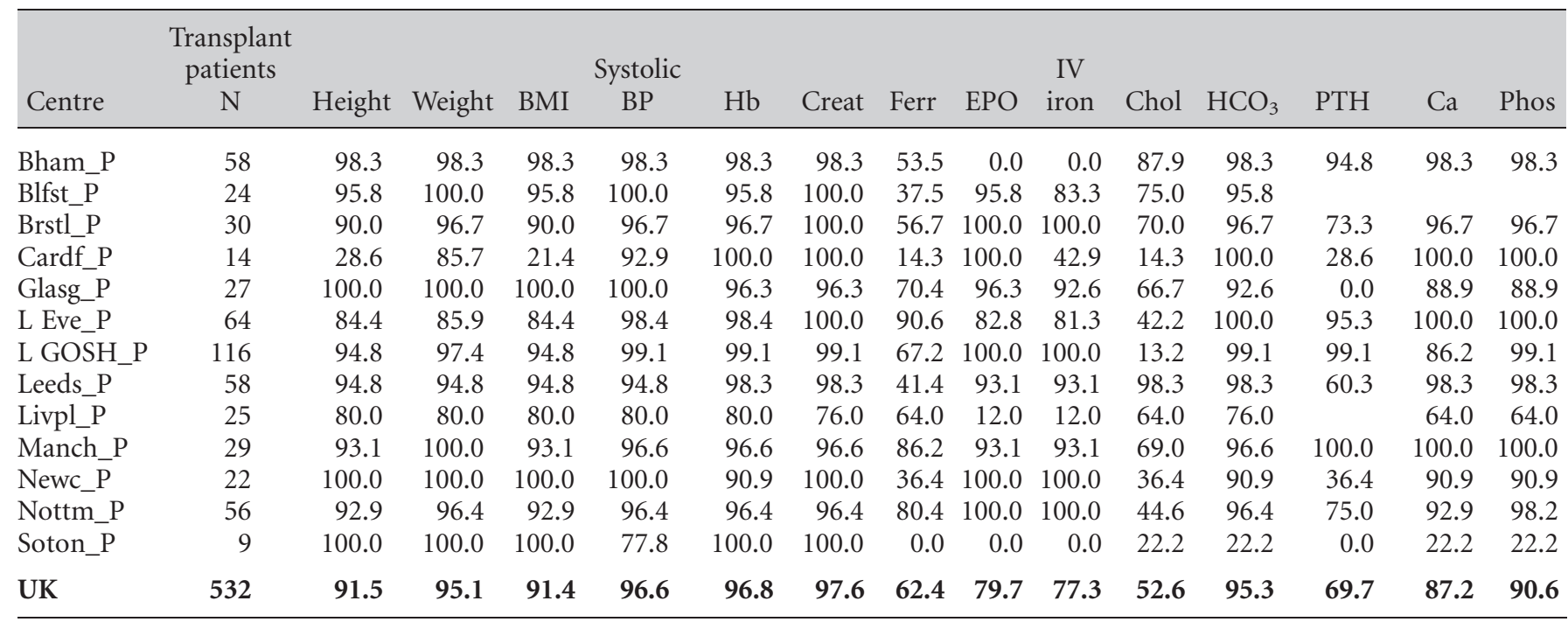

Blank cells represent data items that could not be sent by centres due to technical reasons

especially from Cardiff and GOSH although it is hoped that analysis of this data may be feasible in next year's report.

In 2011, Southampton and Newcastle continued to provide a limited dataset due to a combination of technical difficulties and limited resources resulting in their respective low completion percentages.

\section{Height, weight and BMI}

Figures 7.1 and 7.4 show that children receiving renal replacement therapy were short for their age; those on dialysis were significantly shorter that those with renal transplants. The overall median $\mathrm{z}$-score was -1.20 in the transplanted group and -2.0 in the dialysis group, $\mathrm{p}<0.0001$.

Children with a functioning kidney transplant had a normal weight (median z-score of 0.0), (figure 7.2), whilst those on dialysis had a significantly lower weight than that of healthy children with a median z-score of -1.0 (figure 7.5), $\mathrm{p}<0.0001$.

Body mass index in children with a functioning transplant in 2011 showed inter-centre variation with a

Table 7.4. Percentage data completeness for dialysis patients $<16$ years old by centre for each variable and total number of patients per centre in 2011

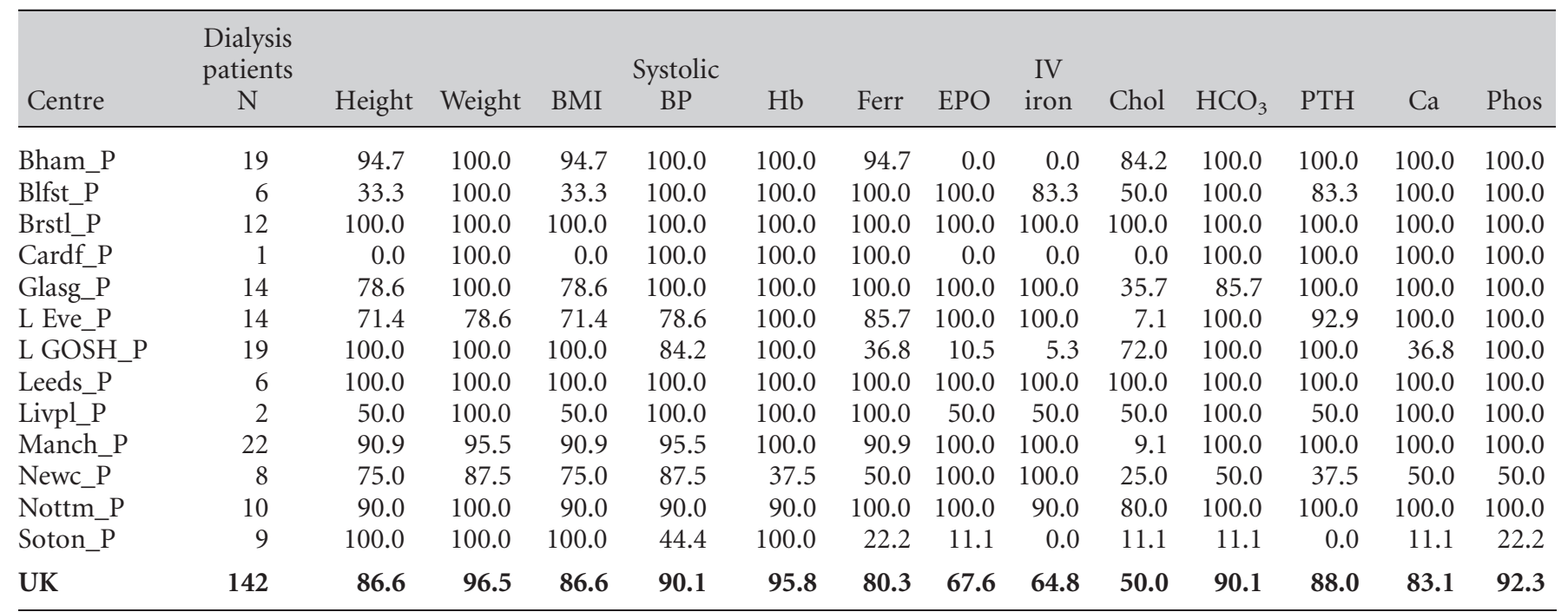

Blank cells represent data items that could not be sent by centres due to technical reasons 

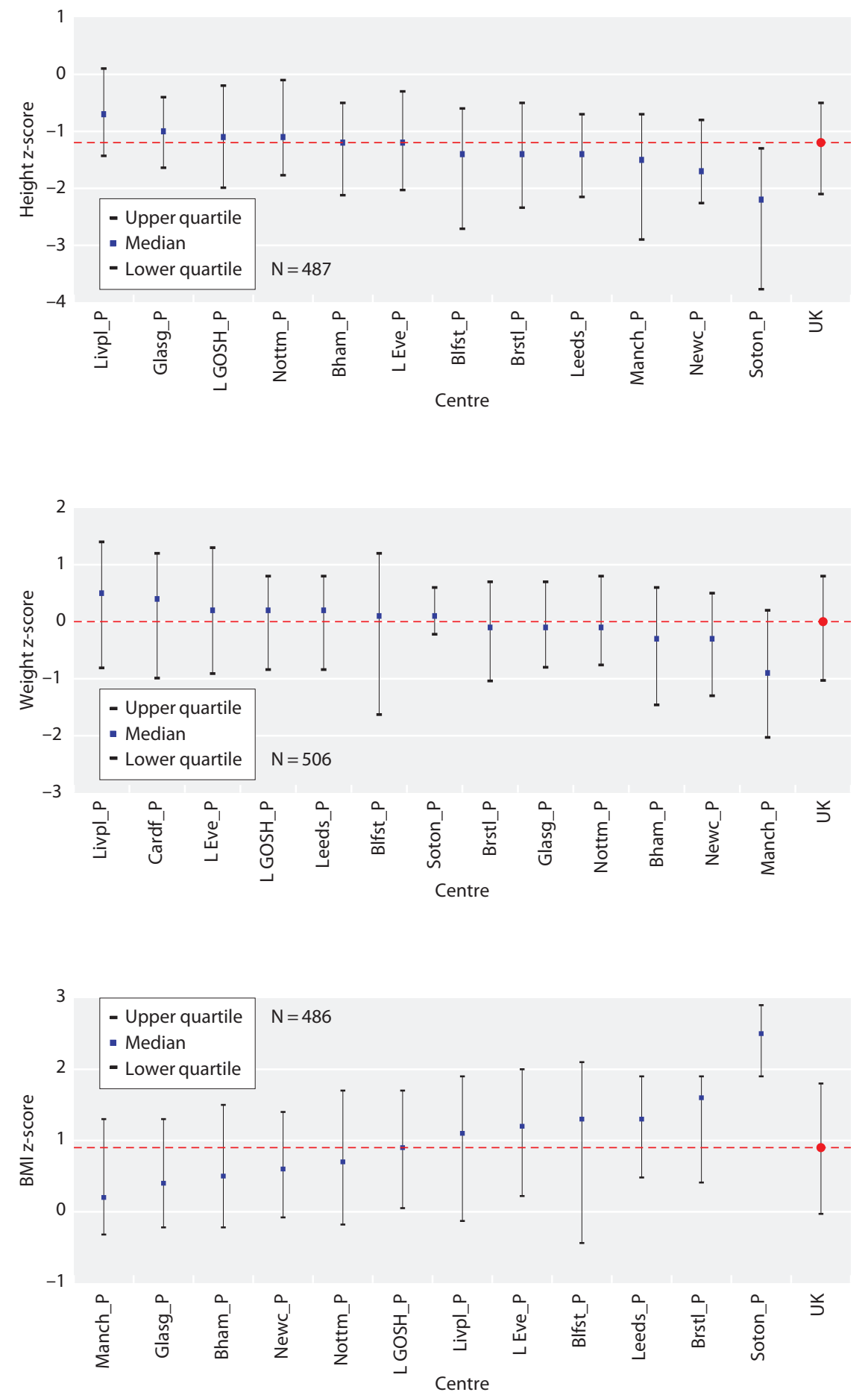

Fig. 7.1. Median height $\mathrm{z}$-scores for transplant patients $<16$ years in 2011 Centres with less than $50 \%$ data completeness were excluded from the centre specific analysis but were included in the UK totals

Fig. 7.2. Median weight $\mathrm{z}$-scores for transplant patients $<16$ years in 2011

Fig. 7.3. Median BMI z-scores for transplant patients $<16$ years in 2011 Centres with less than $50 \%$ data completeness were excluded from the centre specific analysis but were included in the UK totals median z-score of 0.90 (figure 7.3) which was significantly higher than the median BMI z-score in those on dialysis which was near normal at 0.20 (figure 7.6), $\mathrm{p}=0.0002$. These data indicate that in the group as a whole, children on dialysis have less excess weight for height with a BMI z-score close to zero, whereas transplanted children have more excess weight for height.

Table 7.5 shows that $28.3 \%$ of patients with a functioning transplant had a height $<2 \mathrm{SD}$, which was significantly lower than those on haemodialysis 

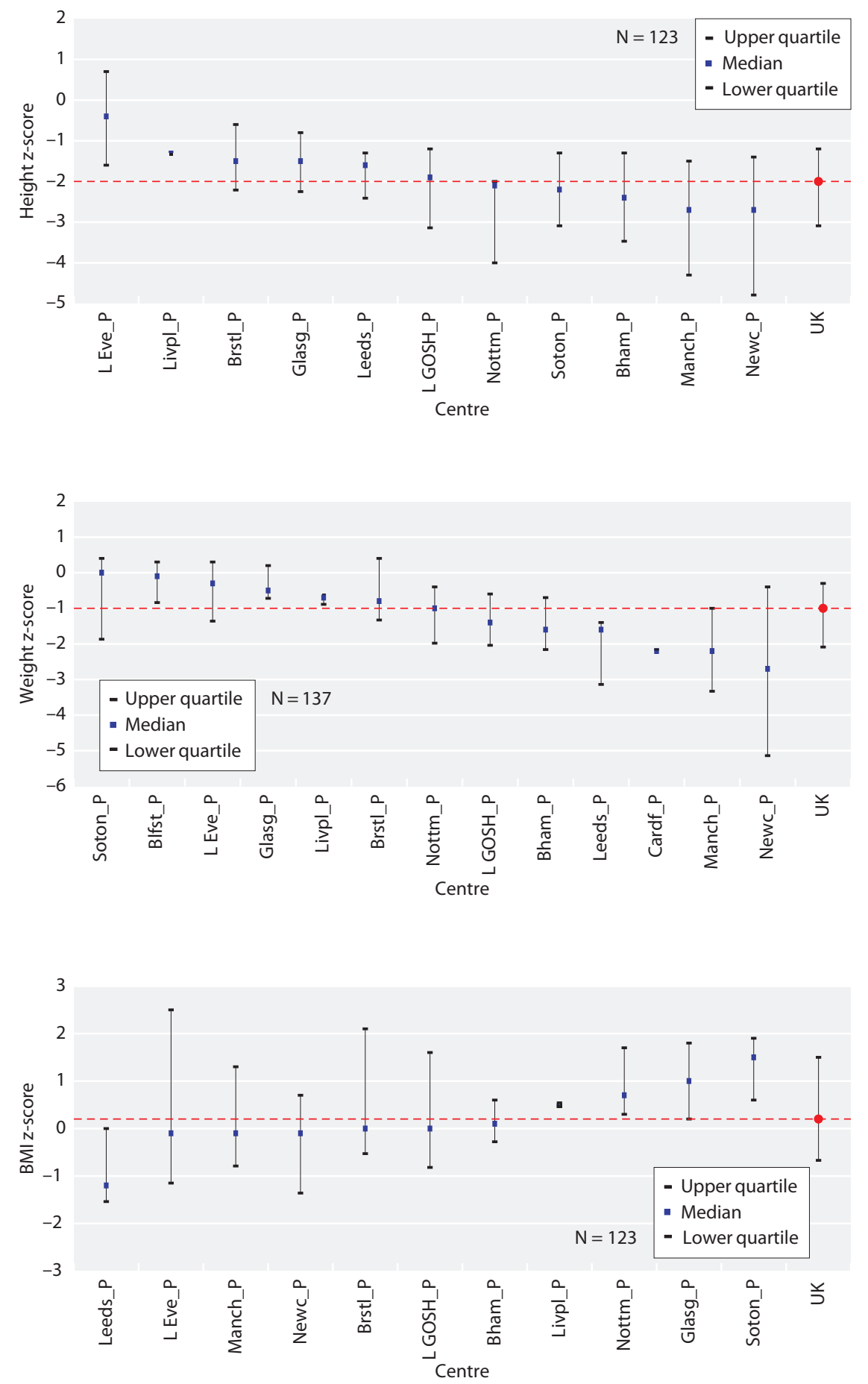

Fig. 7.4. Median height $\mathrm{z}$-scores for dialysis patients $<16$ years in 2011 Centres with less than $50 \%$ data completeness were excluded from the centre specific analysis but were included in the UK totals

Fig. 7.5. Median weight $\mathrm{z}$-scores for dialysis patients $<16$ years in 2011

Fig. 7.6. Median BMI z-scores for dialysis patients $<16$ years in 2011

Centres with less than $50 \%$ data completeness were excluded from the centre specific analysis but were included in the UK totals

(54.0\%) and those on peritoneal dialysis (48.0\%). Analysis by age showed that amongst dialysis patients the greatest proportion of children with a height $<2 \mathrm{SD}$ was in the $0-4.99$ years age group, this was not noted in the transplanted group where age did not appear to make a difference.
Figure 7.7 shows the use of growth hormone in children under 16 years with a height under 2SD in the UK between 2001 and 2011, a significant proportion of these children did not receive growth hormone. Only $31.3 \%$ of dialysis patients with a height below the normal range and $10.0 \%$ with a functioning 
Table 7.5. Percentage of patients $<16$ years with height under 2 SDs in 2011

\begin{tabular}{|c|c|c|c|c|c|c|}
\hline \multirow[b]{2}{*}{ Centre } & \multicolumn{2}{|c|}{ Transplant patients } & \multicolumn{2}{|c|}{ Haemodialysis patients } & \multicolumn{2}{|c|}{ Peritoneal dialysis patients } \\
\hline & Patients with data $\mathrm{N}$ & $\%<2 \mathrm{SD}$ & Patients with data $\mathrm{N}$ & $\%<2 \mathrm{SD}$ & Patients with data $\mathrm{N}$ & $\%<2 \mathrm{SD}$ \\
\hline Bham_P & 57 & 29.8 & 10 & 90.0 & 8 & 37.5 \\
\hline Blfst_P & 23 & 43.5 & & & 2 & 50.0 \\
\hline Brstl_P & 27 & 37.0 & 5 & 20.0 & 7 & 42.9 \\
\hline Cardf_P ${ }^{\text {a }}$ & & & $\mathrm{n} / \mathrm{a}$ & $\mathrm{n} / \mathrm{a}$ & & \\
\hline Glasg_P & 27 & 14.8 & 2 & 50.0 & 9 & 33.3 \\
\hline L Eve_P & 54 & 25.9 & 4 & 0.0 & 6 & 33.3 \\
\hline L GOSH_P & 110 & 23.6 & 10 & 40.0 & 9 & 55.6 \\
\hline Leeds_P & 55 & 29.1 & 2 & 0.0 & 4 & 50.0 \\
\hline Livpl_P & 20 & 20.0 & & & 1 & 0.0 \\
\hline Manch_P & 27 & 37.0 & 6 & 66.7 & 14 & 64.3 \\
\hline Newc_P & 22 & 31.8 & 3 & 100.0 & 3 & 33.3 \\
\hline Nottm_P & 52 & 23.1 & 4 & 75.0 & 5 & 60.0 \\
\hline Soton_P & 9 & 55.6 & 4 & 50.0 & 5 & 60.0 \\
\hline $\mathrm{UK}^{\mathrm{b}}$ & 487 & 28.3 & 50 & 54.0 & 73 & 48.0 \\
\hline \multicolumn{7}{|l|}{ Age group } \\
\hline $0-4.99$ years & 36 & 27.8 & 13 & 84.6 & 35 & 54.3 \\
\hline 5-11.99 years & 222 & 28.8 & 16 & 50.0 & 20 & 45.0 \\
\hline $12-15.99$ years & 229 & 28.0 & 21 & 38.1 & 18 & 38.9 \\
\hline
\end{tabular}

${ }^{a}$ Cardiff did not have any HD patients under 16 in 2011

${ }^{\mathrm{b}}$ If a centre had $<50 \%$ completeness for a treatment group, that centre has been excluded from centre specific analysis, although included in the UK totals

Blank cells denote categories where data completion was $<50 \%$

$\mathrm{n} / \mathrm{a}$ - not applicable

transplant who were short received growth hormone treatment.

\section{Blood pressure}

Analyses of blood pressure management have shown that blood pressure was higher in children receiving renal replacement therapy than in healthy children (figures $7.8,7.9$ ). There was wide inter-centre variation in systolic blood pressure, particularly in dialysis patients with a UK median $\mathrm{z}$-score of 0.70 for dialysis patients and 0.30 for transplant patients.
For children with a functioning kidney transplant, $81.1 \%$ had a systolic BP <90th percentile which was slightly better than last year when $78.6 \%$ of such children achieved the target (table 7.6). In comparison, $66.7 \%$ of children on haemodialysis had a systolic BP $<90$ th percentile whilst $66.2 \%$ of children receiving peritoneal dialysis achieved this (table 7.6). The results for haemodialysis and peritoneal dialysis were slightly worse than those achieved in the previous year $(71.7 \%$ and $74.2 \%$ respectively) although absolute numbers were small. When analysing data by age, blood pressure control

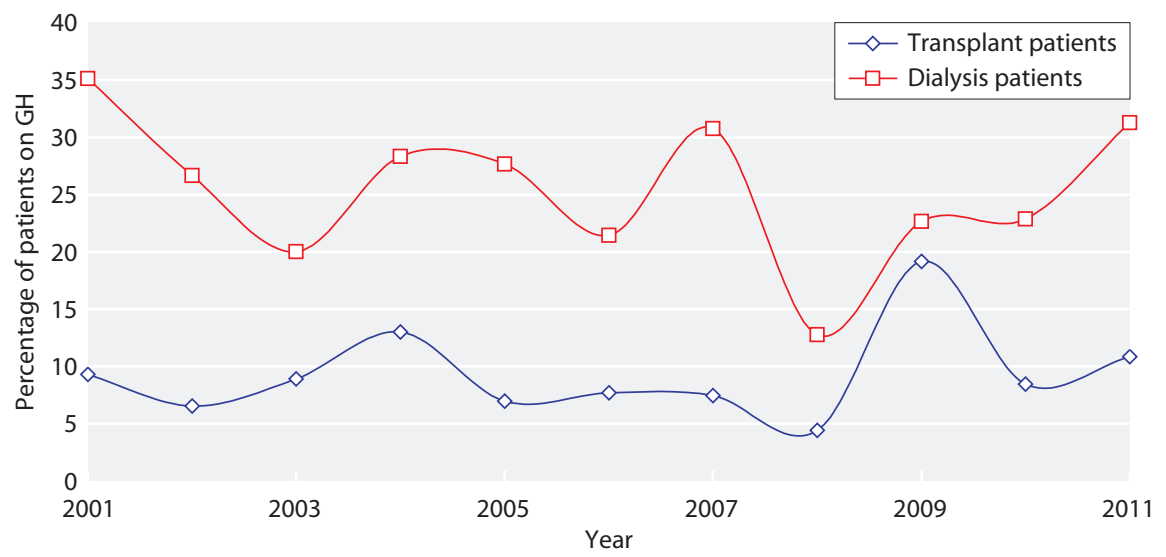

Paediatric Biochemistry 

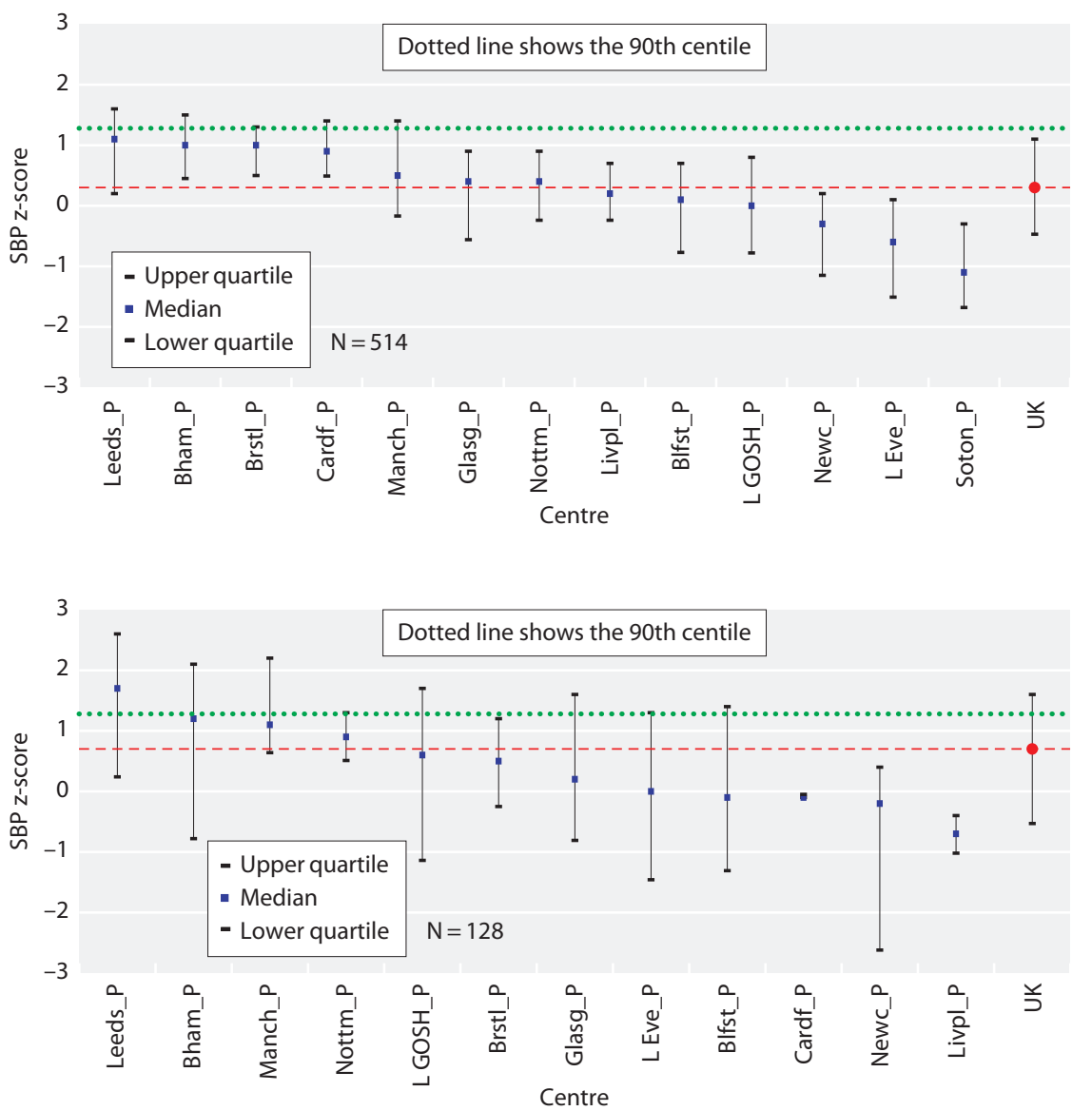

Fig. 7.8. Median systolic blood pressure $\mathrm{Z}$-scores for transplant patients $<16$ years in 2011

Fig. 7.9. Median systolic blood pressure $\mathrm{z}$-scores for dialysis patients $<16$ years in 2011

Centres with less than $50 \%$ data completeness were excluded from the centres specific analysis but were included in the UK totals was slightly worse in the 5-11.99 year age group for dialysis patients with little difference noted amongst transplanted age groups.

\section{Haemoglobin}

The analyses in this report show that many children receiving dialysis were anaemic, with $36.2 \%$ of haemodialysis and $28.2 \%$ of peritoneal dialysis patients having a haemoglobin level below the standard (table 7.7). This compared to only $7.4 \%$ of patients with a functioning transplant having haemoglobin below the standard. Overall there has been a marked reduction in the proportion of children deemed anaemic compared to previous years which was due to using the updated NICE guidelines CG14 (see methods) for this report, as opposed to the previously published guideline (CG 39) which was used in earlier reports (NB analysis of this year's data using the old standard showed no difference this year compared to the previous year).

Analysis by age showed that the proportion of children with a haemoglobin below the standard was greatest for the under 5 years age group for both trans- planted patients and those on haemodialysis. This trend was not statistically significant.

Figure 7.10 shows that the percentage of patients (dialysis and transplanted) achieving or exceeding the treatment standards for haemoglobin has increased over the last decade, more noticeably in dialysis patients. Attainment of ferritin standards (data not shown) during this time shows less of a clear pattern (possibly due to a higher proportion of historical missing data) with a smaller rise noted over time albeit with some fluctuations.

The attainment of the haemoglobin standard in transplant patients was assessed for different levels of graft function (figure 7.11) and with the use of MMF as immunosuppressant therapy (figure 7.12). Figure 7.11 demonstrates that haemoglobin standard attainment was worse for patients with transplant dysfunction with only $80.0 \%$ of patients with an eGFR of $<45$ achieving or exceeding the standard for haemoglobin compared to $95.6 \%$ of patients with an eGFR of $>60$. As for the impact of MMF, figure 7.12 shows that patients using MMF as immunosuppressant therapy were more likely 
Table 7.6. Percentage of patients $<16$ years achieving the standards for systolic blood pressure in 2011

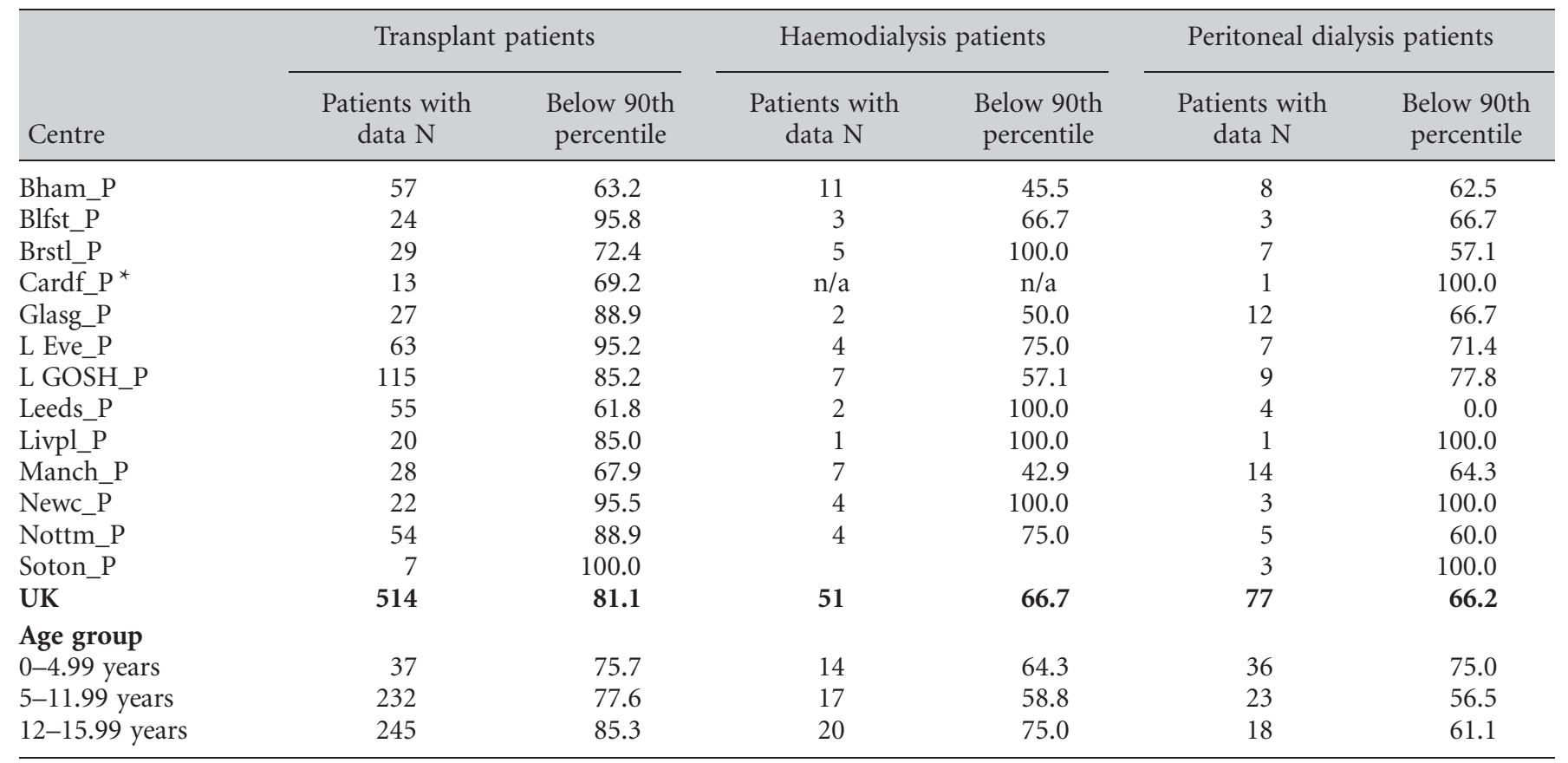

${ }^{\star}$ Cardiff did not have any haemodialysis patients under 16 in 2011

Blank cells denote categories where data completion was $<50 \%$

$\mathrm{n} / \mathrm{a}$ - not applicable

Table 7.7. Percentage of patients $<16$ years old achieving the haemoglobin standard in 2011

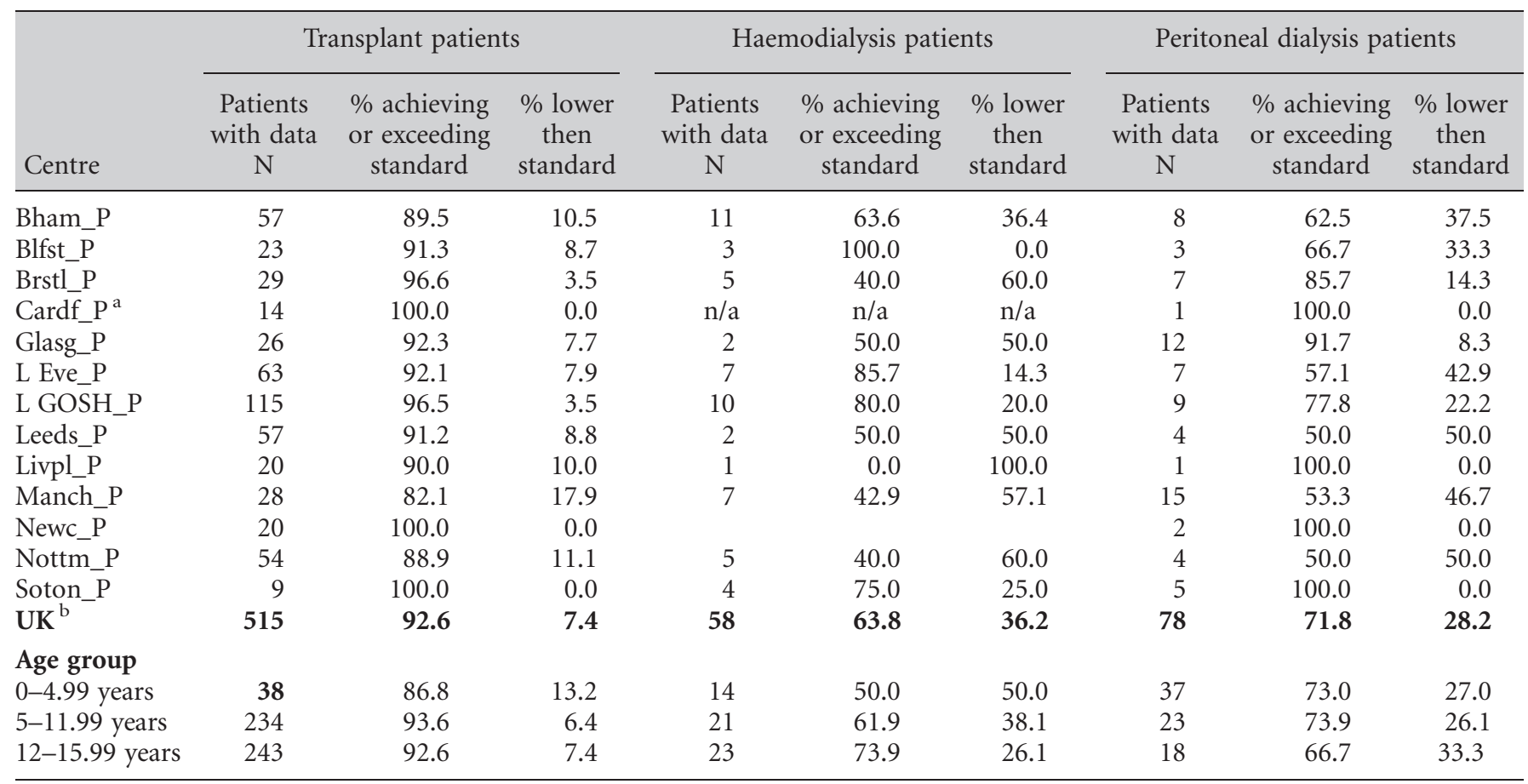

${ }^{a}$ Cardiff did not have any HD patients under 16 in 2011

${ }^{\mathrm{b}}$ If a centre had $<50 \%$ completeness for a treatment group, that centre has been excluded from centre specific analysis, although included in the UK totals

Blank cells denote categories where data completion was $<50 \%$

$\mathrm{n} / \mathrm{a}$ - not applicable 


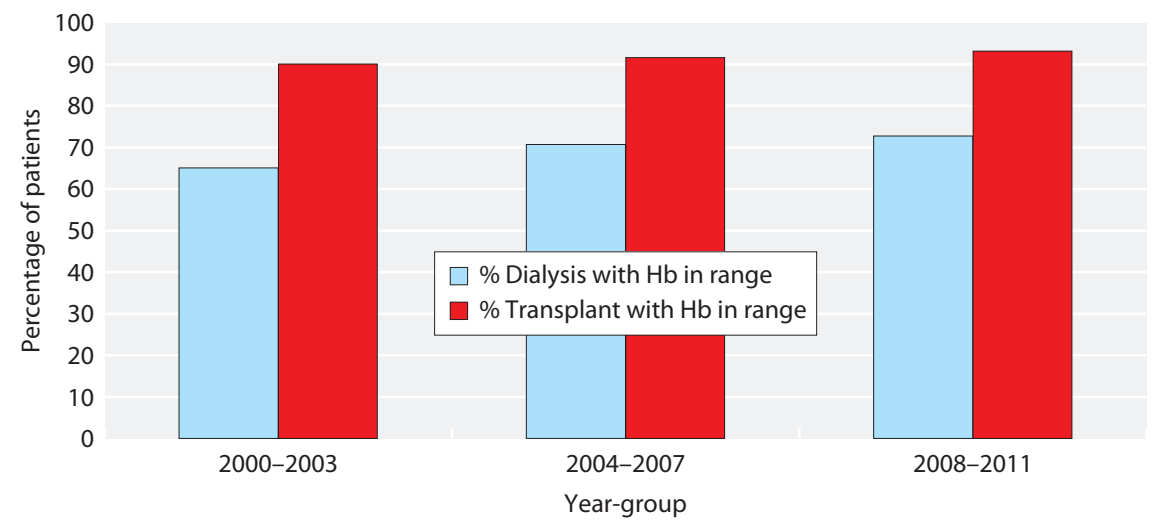

Fig. 7.10. The percentage of patients $<16$ years achieving the treatment standard for haemoglobin between 2000-2011, by treatment modality to have haemoglobin concentrations below the standard, which was statistically significant $\mathrm{p}<0.001$. Whilst this was noted between 2000-2007, this was not seen between 2008-2011, although during this time period there was a marked rise in missing data for MMF (57\% missing data, compared to $15 \%$ during earlier years) making it difficult to draw any significant conclusions.

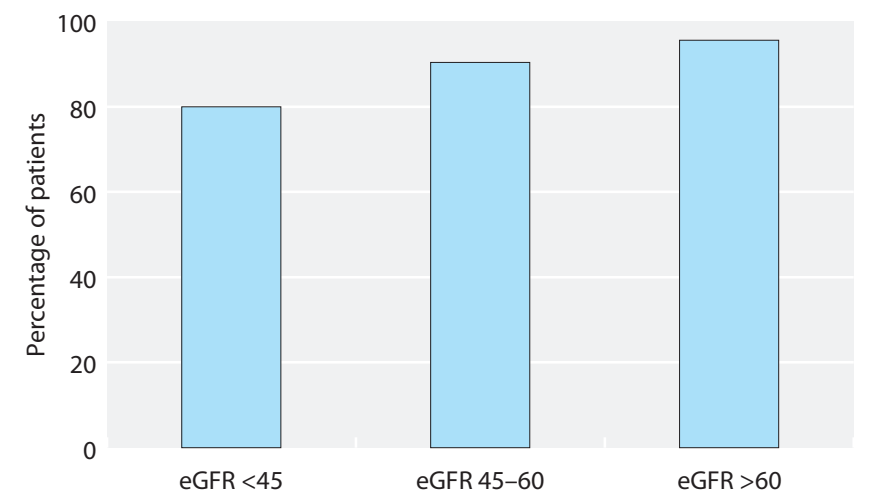

Fig. 7.11. The achievement of haemoglobin treatment standards in paediatric transplant patients $<16$ years, by the level of graft function

This figures combines all data from 2000-2011.

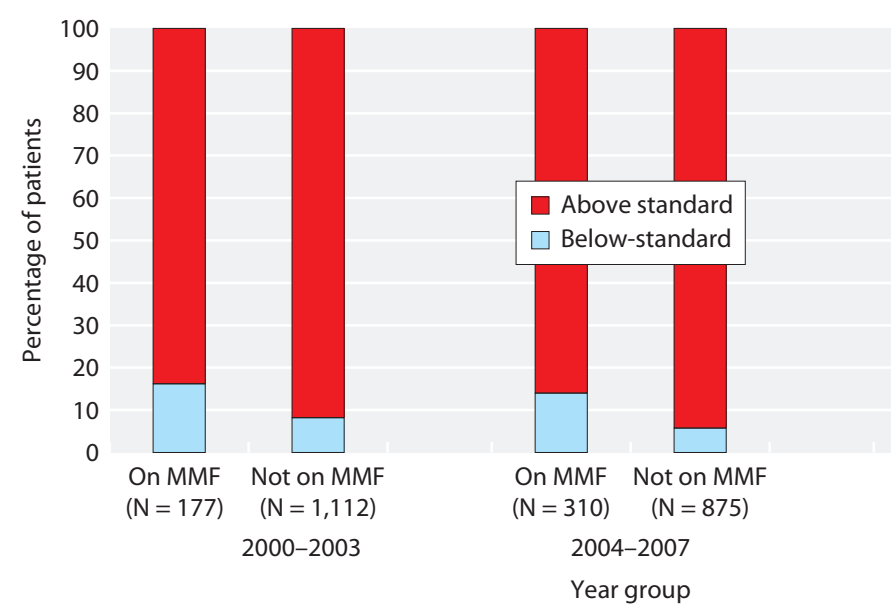

Regarding the use of erythropoietin (ESA) and IV iron, figure 7.13 shows that there has been little change in the use of these agents in transplanted patients over the last decade, although amongst dialysis patients there has been a rise in prescribing both these agents over the last year, reversing the falls noted in the previous two years. Table 7.8 shows that the majority of patients on dialysis (peritoneal or haemodialysis) were on ESA with little change over time. There is a suggestion that more transplant patients were prescribed ESA over time especially if anaemic, however these results should be interpreted with caution as they may be skewed by the fall in data returns for these variables noted this year.

\section{Phosphate, calcium and PTH}

In 2011 in the UK as a whole, 38\% of haemodialysis patients and $62 \%$ of peritoneal dialysis patients had a phosphate within the target range (table 7.9). The achievement of the standard for calcium was better with $63 \%$ of children on haemodialysis and $70 \%$ of children on peritoneal dialysis having a calcium level within the target range (table 7.10). As for PTH, 49\% of children on HD and $46 \%$ on PD had a PTH within

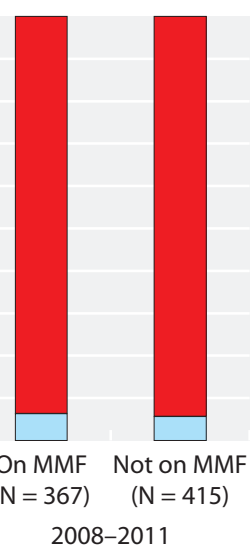

Fig. 7.12. The achievement of haemoglobin treatment standards in paediatric transplant patients $<16$ years, by use of MMF between 2000-2011 


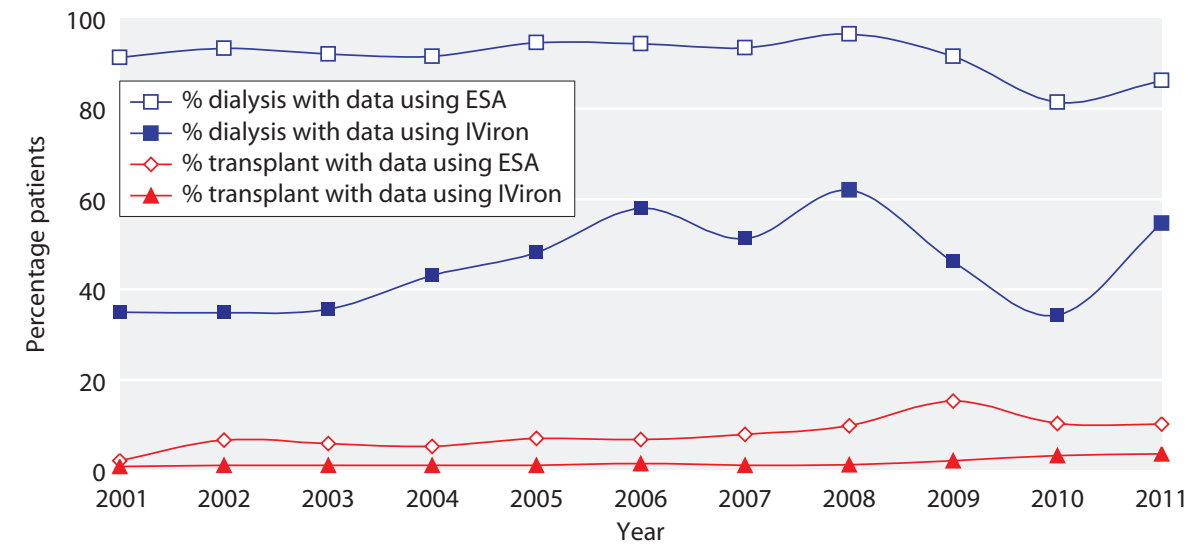

Fig. 7.13. The use of erythropoietin and IV iron in paediatric patients $<16$ years between 2001 and 2011 by treatment modality the target range with wide inter-centre variation (table 7.11). In comparison, $79 \%$ of patients with a functioning transplant achieved a PTH within the target range. Caution should be exercised in the interpretation of these analyses as these analyses represent measurements performed once per year per patient. Further, there are differences between assays used at different centres which may further complicate interpretation of results. No significant age related differences were observed.

\section{Discussion}

There is a continuing move to electronic reporting with many centres now having electronic systems, albeit currently without the facility for automatic data extraction. As this is developed over the coming years, it will allow downloads of data at multiple time points per year for each patient allowing more meaningful analyses. The first step of this process, development of an updated paediatric dataset, is now complete.

Table 7.8. Proportion of paediatric RRT patients on ESA, by haemoglobin attainment, across time

\begin{tabular}{lcc}
\hline Time period & $\begin{array}{c}\text { Hb below standard } \\
\text { \% on ESA }\end{array}$ & $\begin{array}{c}\text { Hb above standard } \\
\text { \% on ESA }\end{array}$ \\
\hline Transplant patients & & \\
2000-2003 & 14.6 & 3.5 \\
2004-2007 & 21.7 & 3.6 \\
2008-2011 & 25.5 & 8.1 \\
Dialysis patients & & \\
2000-2003 & 94.0 & 91.3 \\
2004-2007 & 96.6 & 92.8 \\
2008-2011 & 90.3 & 88.3 \\
\hline
\end{tabular}

Paediatric Biochemistry
The data for each section will be discussed below, but often the results throw up as many questions as they answer. There are several areas where more detailed analysis may help to identify obstacles as to why there has been little apparent change in attainment of many standards over the last few years.

\section{Anthropometry}

Children on renal replacement therapy are short for their age. The cross-sectional data presented here are little different from previous reports; indeed there appears to have been little change since 1999 which is disappointing [6]. Similarly, there has been little change in weight SDs and BMI SDs since 1999 in both transplanted children and those on dialysis.

There may be a number of reasons for this. Over the last few years, there has been an increase in the number of infants and young children receiving RRT. There are also a number of children who have renal failure as part of a syndrome who are often particularly short and their growth may not pick up following transplantation. Indeed one of the shortcomings of the current analyses is the inclusion of children with syndromes, those born prematurely and those aged $<2$ years on RRT, although their overall numbers are likely to be small. However, there have also been initiatives to try and improve growth, such as using rhGH, improved nutrition and avoiding the use of steroids post transplant. This low uptake of rhGH within the UK ERF population where overall $32.8 \%$ of patients have a height below the normal range, remains disappointing. Further, it may be that many different factors not included here have an influence on growth and that further in depth study is needed to tease out what is happening.

For the first time, the proportion of patients who had a height less that the normal range by treatment modality, 
Table 7.9. Achievement of the phosphate standard in dialysis patients $<16$ years in 2011

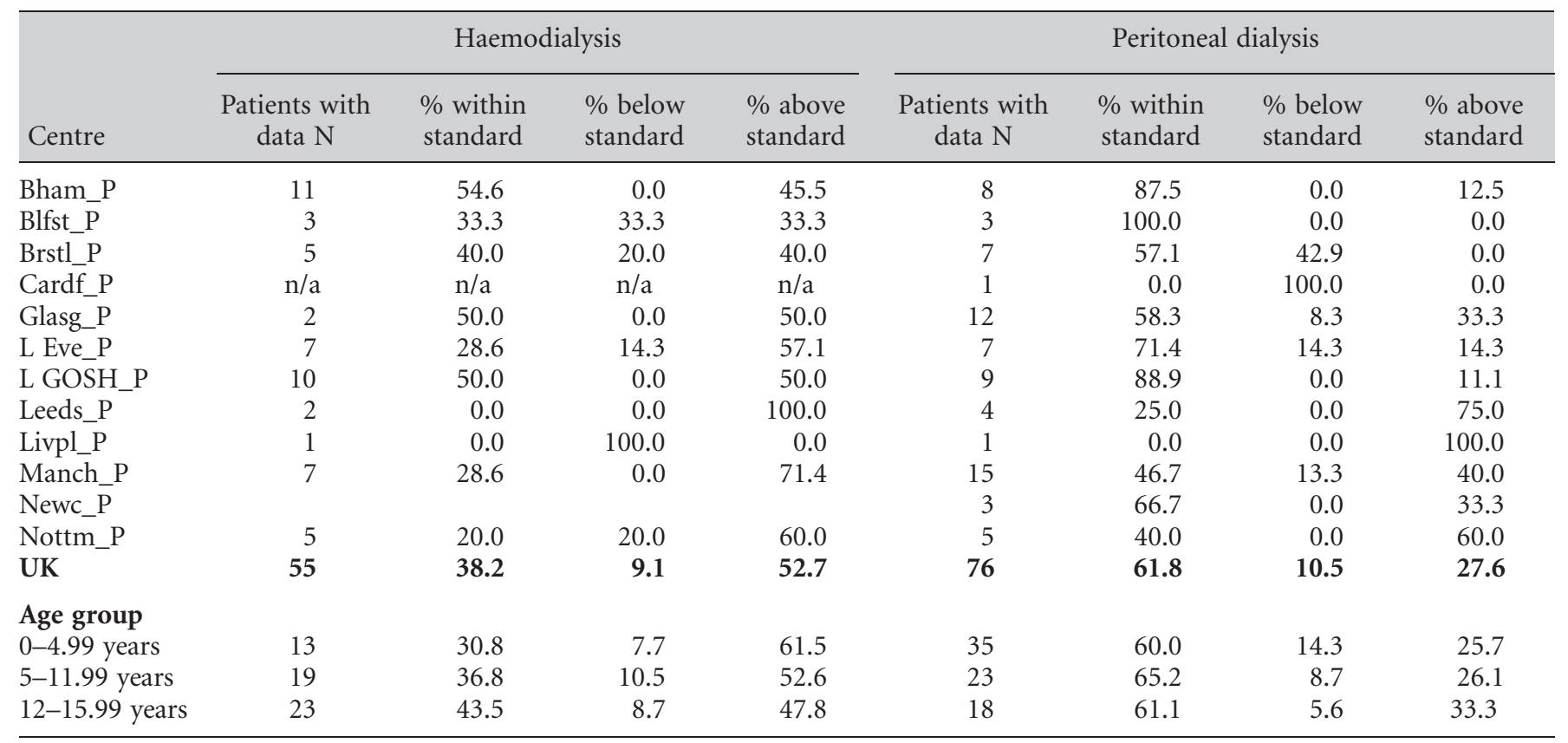

Blank cells denote categories where data completion is $<50 \%$ complete, and thus not displayed n/a not applicable, Cardiff did not have any haemodialysis patients under 16 in 2011

As Southampton had $<50 \%$ completeness for both groups it has been excluded from centre specific analysis, though included in the UK totals

Table 7.10. Achievement of the adjusted calcium standard in dialysis patients $<16$ years in 2011

\begin{tabular}{|c|c|c|c|c|c|c|c|c|}
\hline \multirow[b]{2}{*}{ Centre } & \multicolumn{4}{|c|}{ Haemodialysis patients } & \multicolumn{4}{|c|}{ Peritoneal dialysis patients } \\
\hline & $\begin{array}{c}\text { Patients with } \\
\text { data N }\end{array}$ & $\begin{array}{l}\% \text { within } \\
\text { standard }\end{array}$ & $\begin{array}{l}\% \text { below } \\
\text { standard }\end{array}$ & $\begin{array}{l}\% \text { above } \\
\text { standard }\end{array}$ & $\begin{array}{l}\text { Patients with } \\
\text { data N }\end{array}$ & $\begin{array}{l}\text { \% within } \\
\text { standard }\end{array}$ & $\begin{array}{l}\% \text { below } \\
\text { standard }\end{array}$ & $\begin{array}{l}\% \text { above } \\
\text { standard }\end{array}$ \\
\hline Bham_P & 11 & 54.6 & 0.0 & 45.5 & 8 & 50.0 & 0.0 & 50.0 \\
\hline Blfst_P & 3 & 66.7 & 0.0 & 33.3 & 3 & 66.7 & 0.0 & 33.3 \\
\hline Brstl_P & 5 & 60.0 & 20.0 & 20.0 & 7 & 71.4 & 14.3 & 14.3 \\
\hline L Eve_P & 7 & 71.4 & 28.6 & 0.0 & 7 & 100.0 & 0.0 & 0.0 \\
\hline L GOS̄H_P & 5 & 80.0 & 20.0 & 0.0 & 2 & & & \\
\hline Leeds_P & 2 & 100.0 & 0.0 & 0.0 & 4 & 100.0 & 0.0 & 0.0 \\
\hline Livpl_P & 1 & 0.0 & 100.0 & 0.0 & 1 & 100.0 & 0.0 & 0.0 \\
\hline Manch_P & 6 & 33.3 & 16.7 & 50.0 & 15 & 46.7 & 13.3 & 40.0 \\
\hline Newc_P & 1 & & & & 3 & 66.7 & 0.0 & 33.3 \\
\hline $0-4.99$ years & 11 & 63.6 & 18.2 & 18.2 & 32 & 78.1 & 9.4 & 12.5 \\
\hline 5-11.99 years & 18 & 77.8 & 5.6 & 16.7 & 19 & 68.4 & 5.3 & 26.3 \\
\hline $12-15.99$ years & 19 & 47.4 & 21.1 & 31.6 & 18 & 55.6 & 5.6 & 38.9 \\
\hline
\end{tabular}

${ }^{a}$ Cardiff did not have any HD patients under 16 in 2011

${ }^{\mathrm{b}}$ As Southampton had $<50 \%$ completeness for both groups it has been excluded from centre specific analysis, though included in the UK totals Blank cells denote categories where data completion was $<50 \%$ $\mathrm{n} / \mathrm{a}$ - not applicable 
Table 7.11. Percentage of patients $<16$ years achieving the PTH standard in 2011

\begin{tabular}{|c|c|c|c|c|c|c|c|c|c|}
\hline \multirow[b]{2}{*}{ Centre } & \multicolumn{3}{|c|}{ Transplant patients } & \multicolumn{3}{|c|}{ Haemodialysis patients } & \multicolumn{3}{|c|}{ Peritoneal dialysis patients } \\
\hline & $\begin{array}{c}\text { Patients } \\
\text { with data } \\
\mathrm{N}\end{array}$ & $\begin{array}{c}\% \\
\text { achieving } \\
\text { standard }\end{array}$ & $\begin{array}{c}\% \\
\text { above } \\
\text { standard }\end{array}$ & $\begin{array}{c}\text { Patients } \\
\text { with data } \\
\text { N }\end{array}$ & $\begin{array}{c}\% \\
\text { achieving } \\
\text { standard }\end{array}$ & $\begin{array}{c}\% \\
\text { above } \\
\text { standard }\end{array}$ & $\begin{array}{c}\text { Patients } \\
\text { with data } \\
\text { N }\end{array}$ & $\begin{array}{c}\% \\
\text { achieving } \\
\text { standard }\end{array}$ & $\begin{array}{c}\% \\
\text { above } \\
\text { standard }\end{array}$ \\
\hline Bham_P & 55 & 40.0 & 60.0 & 11 & 45.5 & 54.6 & 8 & 25.0 & 75.0 \\
\hline Blfst_P & & & & 2 & 50.0 & 50.0 & 3 & 33.3 & 66.7 \\
\hline Brstl_P & 22 & 90.9 & 9.1 & 5 & 20.0 & 80.0 & 7 & 57.1 & 42.9 \\
\hline Cardf_P $\mathrm{P}^{\mathrm{a}}$ & & & & & & & 1 & 0.0 & 100.0 \\
\hline Glasg_P & & & & 2 & 50.0 & 50.0 & 12 & 41.7 & 58.3 \\
\hline L Eve_P & 61 & 93.4 & 6.6 & 6 & 50.0 & 50.0 & 7 & 42.9 & 57.1 \\
\hline L GOSH_P & 115 & 89.6 & 10.4 & 10 & 50.0 & 50.0 & 9 & 100.0 & 0.0 \\
\hline Leeds_P ${ }^{-}$ & 35 & 57.1 & 42.9 & 2 & 100.0 & 0.0 & 4 & 75.0 & 25.0 \\
\hline Livpl_P & & & & & & & 1 & 0.0 & 100.0 \\
\hline Manch_P & 29 & 93.1 & 6.9 & 7 & 42.9 & 57.1 & 15 & 20.0 & 80.0 \\
\hline Newc_P & & & & & & & 2 & 100.0 & 0.0 \\
\hline Nottm_P & 42 & 76.2 & 23.8 & 5 & 60.0 & 40.0 & 5 & 40.0 & 60.0 \\
\hline $\mathrm{UK}^{\mathrm{b}}$ & 371 & 79.0 & 21.0 & 51 & 49.0 & 51.0 & 74 & 46.0 & 54.1 \\
\hline \multicolumn{10}{|l|}{ Age group } \\
\hline $0-4.99$ years & 31 & 83.9 & 16.1 & 13 & 15.4 & 84.6 & 34 & 41.2 & 58.8 \\
\hline $5-11.99$ years & 171 & 78.4 & 21.6 & 18 & 66.7 & 33.3 & 23 & 52.2 & 47.8 \\
\hline $12-15.99$ years & 169 & 78.7 & 21.3 & 20 & 55.0 & 45.0 & 17 & 47.1 & 52.9 \\
\hline
\end{tabular}

${ }^{a}$ Cardiff did not have any HD patients under 16 in 2011

${ }^{\mathrm{b}}$ As Southampton had $<50 \%$ completeness for both groups it has been excluded from centre specific analysis, though included in the UK totals Blank cells denote categories where data completion was $<50 \%$

by centre and by age are presented. Twenty eight percent of transplant patients, $54 \%$ of HD patients and $48 \%$ of PD patients had a height that was below the normal range. Children aged less than 5 who were on dialysis seem to be worst affected. Only a third of dialysis patients, and $11 \%$ of transplant patients, who were short for their age, were on growth hormone treatment. There is therefore scope to increase the use of rhGH in these patients. Whilst the figure on $\mathrm{rhGH}$ in the transplant group was low, it is important to remember that these data are cross-sectional and although some children are short, they may be growing at a rate above normal and therefore would not fall into the category for whom rhGH is appropriate. An analysis evaluating final adult height may add to our understanding. The proportion of short transplanted children varied by centre and it would be interesting to see if this relates to the centres' likelihood of using steroids post transplant.

\section{Blood pressure}

There is an increasing body of evidence supporting the role of good blood pressure control in the management of CKD $[7,8]$. There is also an increasing awareness of the importance of cardiovascular morbidity in paediatric patients with CKD and ERF. Overall, there remains scope for improvement in BP control. As BP changes during childhood, it is important to calculate centiles in the clinic rather than using the absolute measurements alone. The authors hope that it may be possible at some point to include the degree of proteinuria for transplant patients.

There was a wide range of median systolic BP scores in different centres and it might be helpful to reflect on the different strategies in each centre and their effect on outcomes. Once again the authors would highlight that these data reflect single measurements per year often performed using BP instruments that employ different techniques.

\section{Anaemia}

A significant proportion of dialysis patients were anaemic; this is little changed from previous reports. The proportion of transplant patients with a haemoglobin within the recommended range however has improved and is due to the change in standard used.

For transplant patients, the chances of a haemoglobin level below the standard were greater with reduced GFR and with the use of MMF. This highlights the importance of calculating GFR for transplant patients, rather than 
using creatinine alone. A lower GFR should highlight the need to check that the haemoglobin is within the recommended range. Since 2000, the proportion of patients with a haemoglobin within range who were on MMF has increased, though with the increase in missing data for use of MMF in the last few years, it makes it difficult to draw any firm conclusions.

Whilst there are indicators to help identify those transplant patients at risk of anaemia, it is more difficult to highlight those at risk within the dialysis populations. Patients on HD seem more at risk and the risk of anaemia may be higher for those aged less than five years. Of those with a haemoglobin below range, over $90 \%$ of patients were on ESAs, although the proportion on IV iron or with a low ferritin is less clear. Of transplant patients with a low haemoglobin, $25 \%$ were now on ESAs compared with $14.6 \%$ between 2000-2003.

It is important to highlight here that it is beyond the scope of the registry to be able to report on dose adjustments that would likely improve understanding of these data. It would be helpful to study dialysis patients in more detail to see if there are any factors which help identify those children at highest risk of anaemia. Detailed data on ferritin and IV iron would be needed for this subgroup of patients. The results of the recently completed national audit on anaemia in the UK paediatric ERF population may help to shed some further light on this.

\section{Biochemistry}

The numbers of paediatric patients on dialysis were small but phosphate control appears to be worse in patients on haemodialysis than in patients on PD. Results for calcium were little different between the dialysis groups and approximately half in each group had a PTH above the desired range. This compares to $21 \%$ of transplanted patients. Data were less complete for PTH in the transplant group which might imply that the complications of reduced GFR might sometimes be overlooked in this group of patients. It would be useful to include vitamin D levels in the parameters studied. Moving to multiple time point reporting of data in future reports will allow better interpretation of biochemistry results.

\section{Summary}

In summary, continued efforts are being made to move towards electronic reporting. Whilst this is still not complete, many centres are moving to using electronic systems which incorporate an electronic patient record. These improved electronic platforms have the additional potential to display percentiles and SDs and it may be that these functionalities will help make clinicians aware of patients results and achievement of targeted clinical standards. Automatic calculations of e.g. eGFR in transplant patients may help to point out that some patients have lower GFRs that make them susceptible to anaemia. The likelihood of complete electronic reporting in the near future with plans for quarterly reporting in the format of the recently finalised NEW paediatric dataset will undoubtedly improve quality of data and their reporting, allowing improvements in patient care.

Conflicts of interest: none

\section{References}

1 UK Renal Registry 12th Annual Report (December 2009): Chapter 12 Clinical, Haematological and Biochemical Parameters in Patients receiving Renal Replacement Therapy in Paediatric Centres in the UK in 2008: national and centre-specific analyses. Hussain F, Castledine C, Schalkwyk DV, Sinha MD, Lewis MA, Inward C. Nephron Clin Pract 2010; 115(suppl1):c289-c308

2 Hussain F, Castledine C, Schalkwyk DV, Sinha MD, Lewis MA, Inward C. Nephron Clin Pract 2010;115(suppl 1):c289-c308

- 3 Freeman JV CT, Chinn S et al. Cross sectional stature and weight reference curves for the UK, 1990. Arch Dis Child 1995;73:17-24

4 BAPN clinical standards http://www.bapn.org/clinical_standards.html

5 NICE clinical guideline 114. Anaemia management in people with chronic kidney disease. London: National Institute for Health and Clinical Excellence, 2011
6 Pruthi R, Sinha MD, Casula A, Tse Y, Maxwell H, O’Brien C, Lewis M, Inward C. UK Renal Registry 14th Annual Report (December 2010): Chapter 5 Demography of the UK Paediatric Renal Replacement Therapy Population in 2010. Nephron Clin Prac 2012; 120(suppl 1):c93-c103; DOI: $10.1159 / 000342847$

7 Strict blood-pressure control and progression of renal failure in children, ESCAPE Trial Group, N Engl J Med. 2009 Oct 22;361(17):1639-50

8 Progression to hypertension in non-hypertensive children following renal transplantation Manish D. Sinha; Julie A. Gilg; Larissa Kerecuk; Christopher J. D. Reid; on behalf of the British Association for Paediatric Nephrology, Nephrology Dialysis Transplantation 2012; doi: 10.1093/ndt/ gfr784 